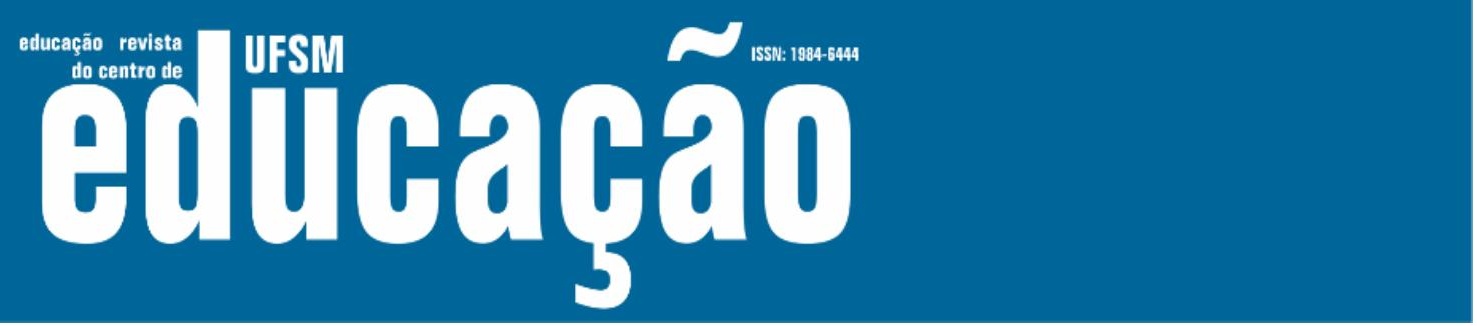

ISSN: 1984-6444 | http://dx.doi.org/10.5902/1984644447465

\title{
Redução e retrocessos na política de tempo integral na escola brasileira: do Programa Mais Educação ao Programa Novo Mais Educação
}

Reductions and setbacks in full-time policy in Brazilian schools: from Programa Mais Educação to Programa Novo Mais Educação

Cintia Aurora Quaresma Cardoso

Universidade Federal do Para, Belém, Pará, Brasil.

cintiacard@yahoo.com.br - https://orcid.org/0000-0002-8929-1523

Ney Cristina Monteiro de Oliveira

Professora Doutora na Universidade Federal do Pará, Belém, Pará, Brasil.

neycmo@ufpa.br - http://orcid.org/0000-0002-8091-5213

Recebido em 19 de junho de 2020

Aprovado em 22 de fevereiro de 2021

Publicado em 27 de janeiro de 2022

\section{RESUMO}

O estudo tem como objetivo analisar comparativamente os macrocampos temáticos do Programa Mais Educação (PME) e do Programa Novo Mais Educação (PNME), no que se refere à proposta de formação integral do sujeito. Adota metodologicamente uma abordagem qualitativa, por meio de revisão bibliográfica e estudo documental. Os dados revelam que o PME, criado em 2007, foi a primeira tentativa a nível nacional de uma política pública de indução da educação integral, mas, apresentou percalços durante sua implementação e permanência nas escolas, decorrentes de problemas estruturais na educação pública brasileira. Em 2016, o Programa foi substituído pelo PNME; neste, embora se tenha incorporado, da versão anterior, os macrocampos Esporte, Lazer, Arte e Cultura, estas atividades têm como objetivo impulsionar a melhoria da aprendizagem do Português e da Matemática, o que evidencia uma matriz formativa reduzida à dimensão cognitiva de conteúdos curriculares relativos apenas à leitura e ao cálculo matemático, para serem testados nas avaliações nacionais, distante, assim, do ideal de formação plena do indivíduo.

Palavras-chave: Educação Integral; Macrocampos temáticos; Mais Educação. 


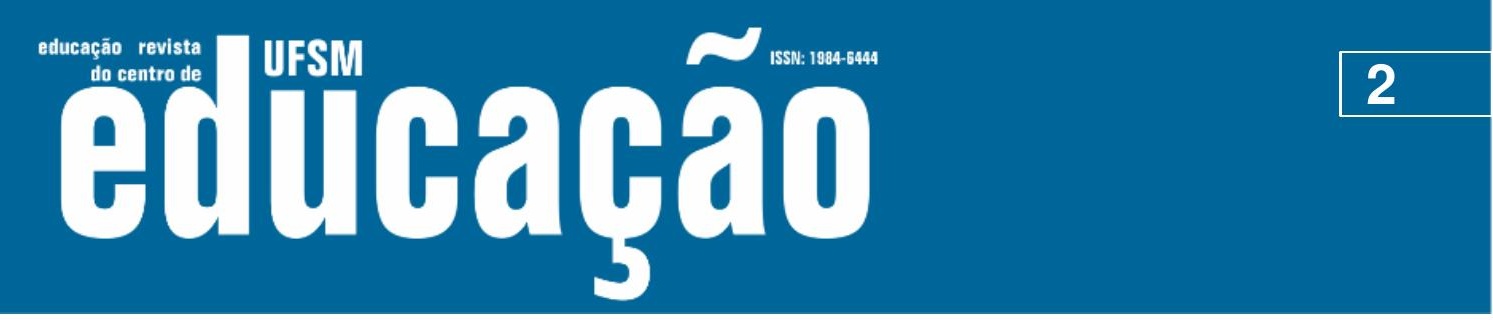

ISSN: 1984-6444 | http://dx.doi.org/10.5902/1984644447465

\section{ABSTRACT}

The study aims to comparatively analyze the macrofields of the More Education Program (Programa Mais Educação - PME) and the New More Education Program (Programa Novo Mais Educação - PNME), regarding the proposal of integral education of the subject. Methodologically adopts a qualitative approach, through bibliographical review and documentary study. The data show that the PME, created in 2007, was the first attempt in a national level of a public policy for the induction of integral education, but it has presented problems during its implementation and permanence in schools, due to structural problems in Brazilian public education. In 2016, the Program was replaced by the PNME; in this one, although the macrofields Sports, Leisure, Art and Culture have been incorporated from the previous version, these activities aim to boost the learning of Portuguese and Mathematics, which shows a formative matrix reduced to the cognitive dimension of curricular contents related only to reading and mathematical calculation, because they are tested in national assessments, thus far from the ideal of full individual formation.

Keywords: Integral Education; Thematic macrofields; Mais Educação.

\section{Introdução}

Este artigo é fruto da pesquisa desenvolvida no mestrado do Programa de PósGraduação em Currículo e Gestão da Escola Básica (PPEB), da Universidade Federal do Pará (UFPA), tendo como objetivo analisar comparativamente os macrocampos temáticos do Programa Mais Educação (PME) e do Programa Novo Mais Educação (PNME), no que se refere à proposta de formação integral do sujeito. $O$ tema se insere nas discussões contemporâneas do direito à educação pública e da formação integral ancorada numa política pública que busque minimizar as desigualdades educacionais (evasão, reprovação, distorção idade/série dos alunos) e sociais, por meio da ampliação do tempo escolar das crianças, adolescentes e jovens, com a oferta de atividades socioeducativas no contraturno escolar.

Quanto ao tipo de pesquisa, tem como abordagem a investigação qualitativa. Esta exige do investigador "que o mundo seja examinado com a ideia de que nada é trivial, que tudo tem potencial para constituir uma pista que nos permita estabelecer uma compreensão mais esclarecedora do nosso objecto de estudo" (BOGDAN; BIKLEN, 1999, p. 49). Desse modo, a abordagem qualitativa, ao entender o fenômeno 


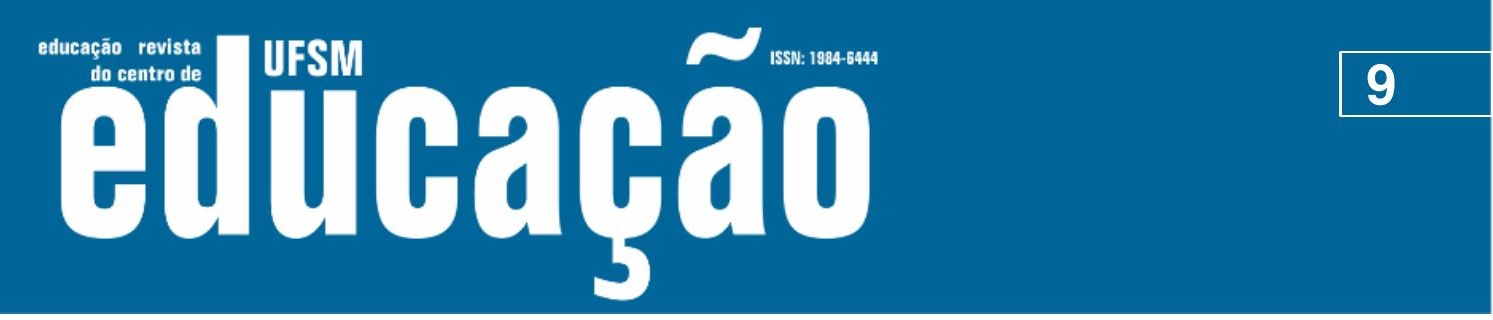

ISSN: 1984-6444 | http://dx.doi.org/10.5902/1984644447465

a precariedade do espaço e da infraestrutura, a formação de profissional, a jornada escolar e o recurso.

Para Mendonça (2017, p. 107), a implantação do PME nas escolas brasileiras colocou em evidência as dificuldades do uso do espaço na ampliação da jornada escolar, pois encontramos nas instituições "[...] insuficiência de banheiros; cozinhas e cantinas inadequadas para servir refeições; uso do pátio e de quadras por um número".

Ainda assim, o governo federal substituiu o PME pelo PNME exclusivamente sob a alegação do não alcance das metas de aprendizagem estabelecidas pelo ldeb, como se esse fosse o único balizador para uma formação integral e instrumento avaliativo para medir a aprendizagem do aluno.

\section{A lógica do Programa Novo Mais Educação: de que educação integral estamos falando?}

O Programa Novo Mais Educação, instituído pelo presidente Michel Temer por meio da Portaria no 1.114/2016 e regido pela Resolução FNDE no 5/2016 (BRASIL, 2016b), propõe a melhoria da aprendizagem em Língua Portuguesa e Matemática no ensino fundamental, com a ampliação da jornada escolar de crianças e adolescentes, mediante a complementação da carga horária de cinco ou quinze horas semanais no turno, ou contra turno escolar.

O novo Programa tinha como uma estratégia do Ministério da Educação para elevar a aprendizagem dos alunos das escolas públicas do ensino fundamental por meio da ampliação de tempos, espaços escolares e oportunidades educacionais (BRASIL, 2017). Para isso, propunha o aumento da jornada escolar de cinco ou quinze horas semanais, no turno e contraturno escolar.

A organização das atividades prevista no PNME era realizada da seguinte maneira: as escolas que fizeram adesão por 5 horas semanais deveriam obrigatoriamente desenvolver 2 (duas) atividades de acompanhamento pedagógico, uma de língua portuguesa, com a carga horária de 2 horas e meia de duração, e outra de matemática, também com 2 horas e meia de duração. Já as instituições que 


\section{Aillbapẫ \\ 3}

ISSN: 1984-6444 | http://dx.doi.org/10.5902/1984644447465

optaram por 15 horas de atividades semanais teriam a oportunidade de realizar as atividades de acompanhamento pedagógico, de língua portuguesa e matemática, ambas com carga horária semanal de 4 horas de duração, além das 3 (três) atividades complementares de livre escolha, nos campos das artes, cultura, esporte e lazer.

Em relação à organização e número de alunos por turma, o PNME indicava que as turmas de acompanhamento pedagógico deveriam ser preenchidas por, no máximo, 20 (vinte) estudantes; já as turmas de atividades complementares devem ser compostas por, no máximo, 30 (trinta) estudantes.

O PNME se desenvolveu na escola de ensino fundamental com acompanhamento pedagógico (orientação de estudos de leitura, escrita, alfabetização e letramento; acompanhamento de matemática) e atividades complementares (nos campos das artes, cultura, esporte e lazer). $\mathrm{O}$ acompanhamento pedagógico era um campo de caráter obrigatório, que buscava a ampliação das oportunidades de aprendizado dos estudantes, com foco na aprendizagem do aluno em Língua Portuguesa e Matemática. Para isso, segundo o documento orientador "devem se valer de metodologias inovadoras e ter como foco a superação dos desafios apontados pela avaliação diagnóstica de cada aluno" (BRASIL, 2016c, p. 8).

Desse modo, compreendemos que, ao priorizar o número menor de alunos e maior carga horária nas atividades de acompanhamento pedagógico, o Programa deixa evidente sua preocupação com as atividades curriculares de língua portuguesa e matemática, delegando menor importância às atividades nos campos das artes, cultura, esporte e lazer.

\section{Macrocampos Temáticos do PME e do PNME}

Com vistas à indução da educação integral, o PME e o PNME tinham suas atividades distribuídas em macrocampos temáticos, os quais apresentaram diferenças quanto à oferta das atividades, decorrentes de sua intencionalidade para a educação, conforme mostramos nos Quadros 1 e 2.

O PME organizou suas atividades em macrocampos e atividades para as escolas urbanas e macrocampos e atividades para as escolas do campo, pois se entendia que 


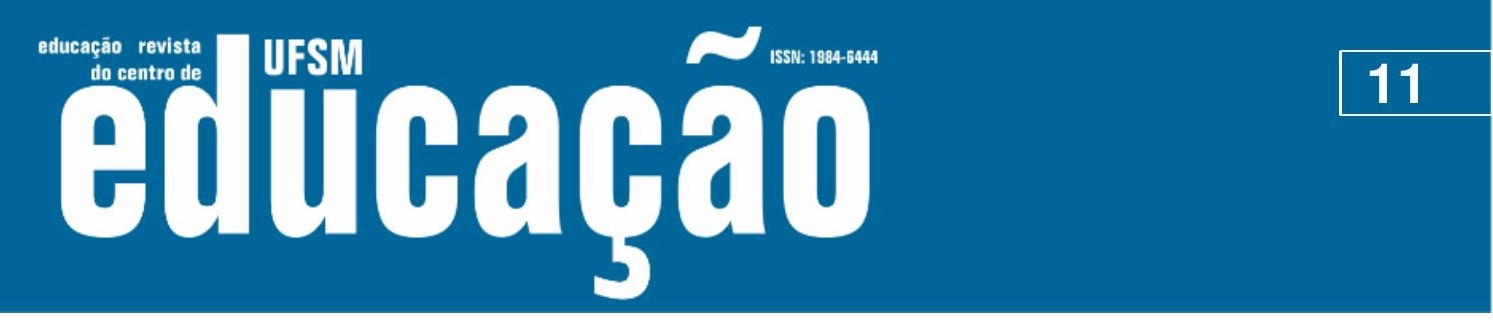

ISSN: 1984-6444 | http://dx.doi.org/10.5902/1984644447465

qualquer proposta que buscasse uma educação de qualidade deveria pensar a realidade local, suas especificidades ambientais e particularidades étnicas adequadas ao modo de viver, pensar e produzir das populações, o que remete a procedimentos específicos na implantação do Programa nas escolas do campo (BRASIL, 2014). Já o PNME dividiu suas atividades, mas, sem fazer distinção entre os macrocampos das escolas do campo e da cidade.

Ao compararmos os macrocampos temáticos ofertados à educação integral dos dois programas, em relação às escolas do campo, percebemos modificações nas atividades socioeducativas, pois, segundo o Manual Operacional de Educação Integral (BRASIL, 2014), o PME apresentava sete macrocampos temáticos de atividades; já o Documento Orientador (BRASIL, 2016c), apenas três. Esses macrocampos são demonstrados no Quadro 1.

Em relação ao acompanhamento pedagógico das escolas do campo, o PME buscava a ampliação das oportunidades de aprendizado aos estudantes por meio de uma atividade única chamada Campos do Conhecimento, a qual deveria abranger todas as áreas de conhecimento, ao contrário do PNME que contempla apenas duas disciplinas curriculares - Português e Matemática.

Quadro 1 - Macrocampos temáticos ofertados à educação integral (escolas do campo)

\begin{tabular}{|l|lc|}
\hline \multicolumn{3}{|c|}{ MACROCAMPOS TEMÁTICOS - ESCOLAS DO CAMPO } \\
\hline PME & PNME \\
\hline Acompanhamento Pedagógico: dá-se por & Acompanhamento Pedagógico: & Língua \\
meio de uma atividade única chamada & Portuguesa e Matemática \\
Campos do Conhecimento, devendo essa & & \\
contemplar todas as áreas de conhecimento: & & \\
Ciências Humanas, Ciências e Saúde, & \\
Etnolinguagem, Leitura e Produção Textual e & \\
Matemática & \\
\hline Agroecologia: Canteiros Sustentáveis; COM- & \\
VIDA - Comissão de Meio Ambiente e & FOI EXCLUÍDO \\
Qualidade de Vida; Conservação do Solo e & \\
Composteira (ou Minhocário); Cuidado com & \\
Animais; Uso Eficiente de Água e Energia & FOI EXCLUÍDO \\
\hline Iniciação Científica & \\
\hline
\end{tabular}




\section{Hism outlathá}

ISSN: 1984-6444 | http://dx.doi.org/10.5902/1984644447465

\begin{tabular}{|c|c|}
\hline $\begin{array}{l}\text { Educação em Direitos Humanos: Arte } \\
\text { audiovisual e corporal, Arte corporal e som, } \\
\text { Arte corporal e jogos, Arte gráfica e literatura, } \\
\text { Arte gráfica e mídias, Arte gráfica e mídia }\end{array}$ & FOI EXCLUÍDO \\
\hline $\begin{array}{l}\text { Cultura, Artes e Educação Patrimonial: } \\
\text { Brinquedos e Artesanato Regional, Canto } \\
\text { Coral, Capoeira, Cineclube, Contos, Danças, } \\
\text { Desenho, Escultura/Cerâmica, Etnojogos, } \\
\text { Literatura de Cordel, Mosaico, Música, } \\
\text { Percussão, Pintura, Práticas Circenses, } \\
\text { Teatro }\end{array}$ & 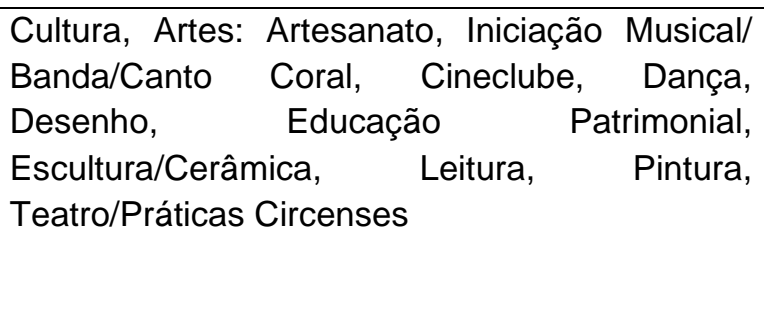 \\
\hline $\begin{array}{l}\text { Esporte e Lazer: Atletismo; Basquete; } \\
\text { Futebol; Futsal; Handebol; Tênis de Mesa; } \\
\text { Voleibol; Xadrez Tradicional; Esporte na } \\
\text { Escola/Atletismo e Múltiplas Vivências } \\
\text { Esportivas; Ciclismo; Corrida de Orientação; } \\
\text { Etnojogos; Judô; Recreação e Lazer/ } \\
\text { Brinquedoteca }\end{array}$ & $\begin{array}{l}\text { Esporte e Lazer: Atletismo, Badminton, } \\
\text { Basquete, Futebol, Futsal, Handebol, Natação, } \\
\text { Tênis de Campo, Tênis de Mesa, Voleibol, Vôlei } \\
\text { de Praia, Capoeira, Xadrez Tradicional, Xadrez } \\
\text { Virtual, Judô, Karatê, Luta Olímpica, } \\
\text { Taekwondo, Ginástica Rítmica }\end{array}$ \\
\hline 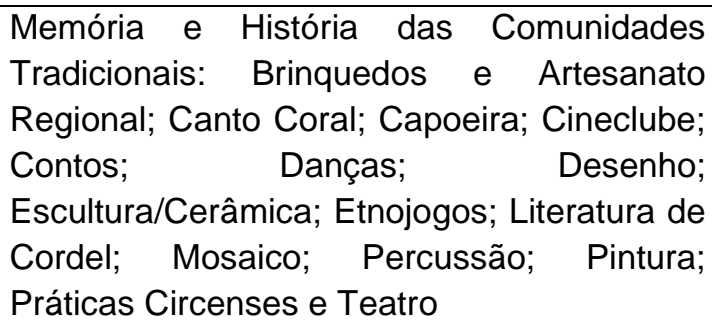 & FOI EXCLUÍDO \\
\hline
\end{tabular}

Fonte: Elaborado pela autora a partir do Manual Operacional de Educação Integral (BRASIL, 2014) e documento orientador (BRASIL, 2016c).

Referente ao macrocampo Esporte e Lazer, identificamos uma redução de atividades, pois, enquanto o PME ofertava número maior de atividades, o PNME eliminou as seguintes: Esporte na Escola/Atletismo e Múltiplas Vivências Esportivas; Ciclismo; Corrida de Orientação, Etnojogos, Recreação e Lazer/Brinquedoteca; embora tenha inserido: Badminton, Natação, Karatê, Luta Olímpica, Taekwondo, e Ginástica Rítmica. Dessas atividades eliminadas, a que nos chama atenção é Etnojogos, por se tratar de uma atividade que valoriza e preserva os jogos tradicionais, brincadeiras e manifestações esportivas regionais, significando com isso desconhecimento dessa modalidade e até mesmo o desrespeito à diversidade etnocultural da população do campo. 


\section{-

ISSN: 1984-6444 | http://dx.doi.org/10.5902/1984644447465

Além disso, nesse macrocampo, o aluno tinha a oportunidade ampliar seu conhecimento sobre cultura digital e tecnológica, visto que há necessidade da inserção do estudante (e da escola) no mundo digital, pois o acesso à tecnologia para todos os segmentos da sociedade se tornou algo imprescindível para o exercício da cidadania, pois sabemos que não podemos pensar a tecnologia com algo distante da escola nem da vida dos sujeitos. Dessa maneira, é fundamental que os alunos tenham acesso às diversas linguagens, inclusive e principalmente, às digitais, considerando que vivemos em um mundo digital e não podemos ser alijados desse processo.

Diante da lógica de funcionamento e dos objetivos do PNME, este se centraliza no saber tradicional e tecnicista com foco na melhoria da aprendizagem dos alunos nas disciplinas de língua portuguesa, ao utilizar como método de avaliação dessas habilidades a realização de testes e relatórios "[...] que visam balizar não apenas as ações pedagógicas desenvolvidas pela escola, como também a formação dos articuladores e mediadores e, também, o acompanhamento da execução do programa" (BRASIL, 2017, p. 37), por meio de indicadores.

Desse modo, constatamos que a concepção de educação integral do PNME é alinhada ao modelo neoliberal e neogerencialista de educação, os quais reproduzem as desigualdades sociais. Nesta relação, o tempo ampliado visa atender à lógica dos resultados quantificáveis dos sistemas padronizados de avaliação, o que não representa os ideais da concepção de educação integral.

\section{Considerações finais}

O PME foi a primeira tentativa a nível nacional de uma política de ampliação do tempo escolar e organização curricular para indução da educação integral, por meio da oferta de atividades diversificadas, incluindo acompanhamento pedagógico, esporte/lazer, cultura/artes; comunicação, uso de mídias e cultura digital e tecnológica, comunicação ambiental desenvolvimento sustentável e economia solidária e criativa/educação econômica, direitos humanos em educação e promoção da saúde. No entanto, durante sua vigência, o Programa apresentou uma gama de problemas decorrentes da herança histórica de décadas de descaso com a educação 


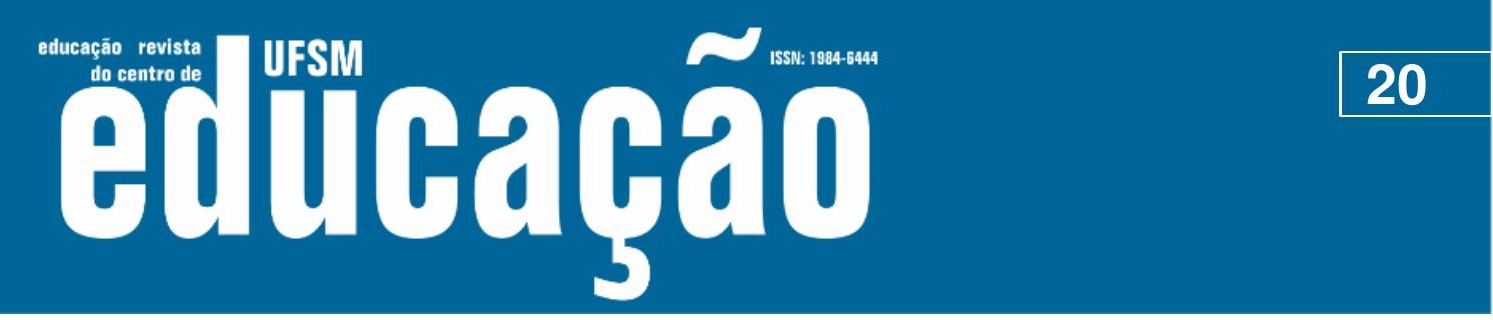

ISSN: 1984-6444 | http://dx.doi.org/10.5902/1984644447465

Desse modo, inferimos que a vigência do PNME e seus macrocampos temáticos trouxe para a educação pública brasileira um retrocesso na busca da formação multidimensional do ser. Em contrapartida, percebemos o avanço na concepção liberal-pragmática de educação, assentada nos ideais meritocráticos, competitivos, de racionalidade e produtividade, dada a ênfase do Programa aos resultados do Ideb. Com isso, o PNME legitima os processos de reconfiguração da educação ao modo de acumulação flexível do capitalismo.

As mudanças arquitetadas no cenário educacional nos últimos anos, como a substituição do PME pelo PNME, e o encerramento deste, sem discussão e orientação à comunidade escolar sobre o rumo da educação e dos programas, revelam a ascensão de uma "nova" política articulada para a educação brasileira, que se materializa e ganha força com a retirada de direitos, com a retomada do autoritarismo e de estímulo à política de atrelamento da educação brasileira aos interesses do grande capital financeiro, a qual busca a todo momento a destruição do que é público e da educação no Brasil, indo na contramão das metas traçadas para a educação nacional constantes do PNE/2014, fruto de árduas lutas dos educadores brasileiros.

\section{Referências}

ALMEIDA, Cristóvão Domingos de; GUINDANI, Joel Felipe; SILVA, Jackson Ronie Sá. Pesquisa documental: pistas teóricas e metodológicas. Revista Brasileira de História \& Ciências Sociais, v. 1, n. 1, jul. 2009.

BOGDAN, Robert C.; BIKLEN, Sari Knopp. Investigação qualitativa em educação: uma introdução à teoria e aos métodos. Porto, Portugal: Porto Editora, 1999.

BRASIL. Decreto no 7.083, de 27 de janeiro de 2010. Dispõe sobre o Programa Mais Educação. Brasília, DF, 2010.2 Disponível em: http://www.planalto.gov.br/ccivil_03/_ato2007-2010/2010/decreto/d7083.htm. Acesso em: 10 set. 2017.

BRASIL. Lei no 13.005, de 25 de junho de 2014. Aprova o Plano Nacional de Educação - PNE e dá outras providências. Brasília, DF, 2014a. Disponível em: http://www.planalto.gov.br/ccivil_03/_ato2011-2014/2014/lei/13005.htm. Acesso em: 21 jan. 2018. 


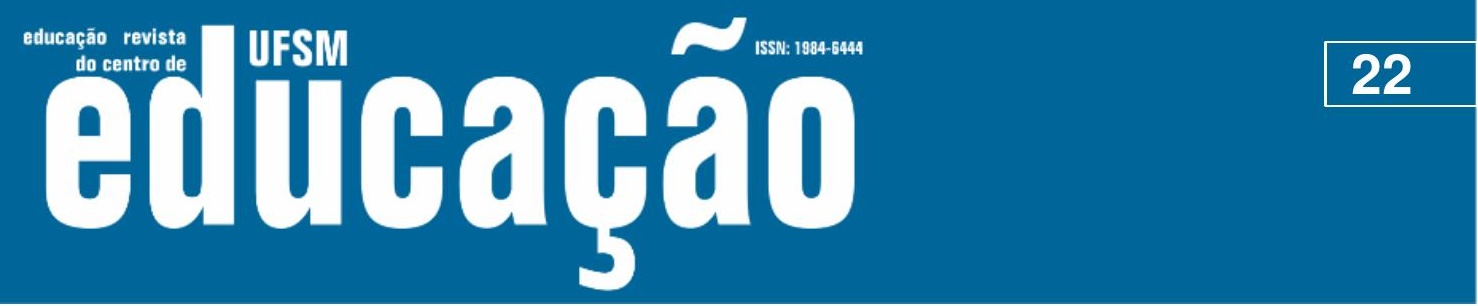

ISSN: 1984-6444 | http://dx.doi.org/10.5902/1984644447465

CURY, Carlos Roberto. Ideologia e Educação Brasileira. 4. ed. São Paulo: Cortez; Autores Associados, 1988.

FRIGOTTO, Gaudêncio. Educação omnilateral. In: CARDART, Roseli Salete et al. Dicionário da Educação do Campo. Rio de Janeiro: Escola Politécnica de Saúde Joaquim Venâncio; São Paulo: Expressão Popular, 2012, p. 266-274.

FUNDAÇÃO ITAÚ SOCIAL. Relatório de avaliação econômica e estudos qualitativos: o Programa Mais Educação, Ministério da Educação. São Paulo: Fundação Itaú Social, 2015. (Avaliação econômica de projetos sociais). Disponível em:

http://www.redeitausocialdeavaliacao.org.br/wpcontent/uploads/2015/11/relat_Mais_Educa\%C3\%A7\%C3\%A3o_COMPLETO_2015 1118.pdf. Acesso em: 15 out. 2018.

JAEGER, Werner Wilhelm. Paidéia: a formação do homem grego. 3. ed. São Paulo: Martins Fontes, 1994.

MENDONÇA, Patricia Moulin. O direito à educação em questão: as tensões e disputas no interior do Programa Mais Educação. 2017. Tese (Doutorado) Faculdade de Educação, Universidade Federal de Minas Gerais, Belo Horizonte, 2017.

MORAES, José Damiro. Educação integral: uma recuperação do conceito libertário. In: COELHO, Ligia Martha Coimbra da Costa (Org.). Educação Integral em Tempo Integral: estudos e experiências em processo. Petrópolis, RJ: DP et alii; Rio de Janeiro, FAPERJ, 2009.

RAYO, José Tuvilla. Educação em Direitos Humanos: rumo a uma perspectiva global. Porto Alegre: Artmed, 2004.

RIBEIRO, Madison Rocha. A relação entre currículo e educação integral em tempo integral: um estudo a partir da configuração curricular do Programa Mais Educação. 2017. Tese (Doutorado) - Programa de Pós-Graduação em Educação, Instituto de Ciências da Educação, Universidade Federal do Pará, Belém, PA, 2017.

SOUSA, Luisete do Espírito Santo. Políticas de ampliação da jornada escolar: a implantação do Programa Mais Educação em Igarapé-Miri/PA. Dissertação (Mestrado) - Programa da Pós-Graduação em Educação, Instituto de Ciências em Educação, Universidade Federal do Pará, Belém, PA, 2016.

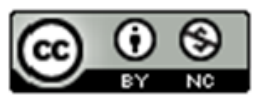

This work is licensed under a Creative Commons Attribution-NonCommercial 4.0 International (CC BY-NC 4.0) 